\title{
The Effects of Two Anesthetics, Propofol and Sevoflurane, on Liver Ischemia/ Reperfusion Injury
}

\author{
Zhijie Xu Jingui Yu Jianbo Wu Feng Qi Huanliang Wang Zhigang Wang \\ Zhou Wang
}

Department of Anesthesiology, Qilu Hospital of Shandong University, Jinan, China

\author{
Key Words \\ Propofol • Sevoflurane $\cdot$ Liver IR • Apoptosis
}

\begin{abstract}
Background: Propofol and sevoflurane are widely used in clinical anesthesia, and both have been reported to exert a protective effect in organ ischemia/reperfusion (IR). This study aims to investigate and compare the effects of propofol and sevoflurane on liver ischemia/reperfusion and the precise molecular mechanism. Methods and Materials: Rats were randomized into four groups: the sham group, I/R group, propofol treatment group (infused with $1 \%$ propofol at $500 \mu \mathrm{g} \cdot \mathrm{kg}-1 \cdot \mathrm{min}-1$ ), and sevoflurane treatment group (infused with $3 \%(2 \mathrm{~L} / \mathrm{min}$ ) sevoflurane). The liver ischemia/reperfusion model was used to evaluate the hepatoprotective effect on ischemic injury. Liver enzyme leakage, liver cytokines and histopathological examination were used to evaluate the extent of hepatic ischemia/reperfusion injury. Oxidative stress was investigated by evaluating the levels of Malondialdehyde(MDA), Superoxide Dismutase(SOD) and NO. The terminal dexynucleotidyl transferase(TdT)-mediated dUTP nick end labeling (TUNEL) assay and western blot were applied to detect apoptosis in the ischemic liver tissue and its mechanism. Results: Both propofol and sevoflurane attenuated the extent of hepatic ischemia/reperfusion injury which is evident from the hisopathological studies and alterations in liver enzymes such as AST and LDH by inhibiting Nuclear factor kappa B (NFKB) activation and subsequent alterations in inflammatory cytokines interleukin-1(IL-1), interleukin-6(IL-6), tumor necrosis factor-alpha (TNF- $\alpha$ ) and increased IL10 release. Propofol exhibited a similar protective effect and a lower IL-1 release, while sevoflurane decreased TNF- $\alpha$ leakage more significantly. Meanwhile, oxidative stress was attenuated by reduced MDA and NO and elevated SOD release. The expression of antiapoptotic protein $\mathrm{BCl}-2$ and $\mathrm{BCl}-\mathrm{xl}$ were enhanced while that of apoptotic protein Bax and Bak were reduced by both propofol and sevoflurane to regulate hepatic apoptosis. In addition, propofol downregulated the phosphorylation of AKT and Bad protein, while sevoflurane downregulated the phosphorylation of p38. In addition,
\end{abstract}




\section{Cellular Physiology Cell Physiol Biochem 2016;38:1631-1642 \\ \begin{tabular}{l|l} 
and Biochemistry Published online: April 28, 2016 & $\begin{array}{l}\text { D } 2016 \text { The Author(s). Published by S. Karger AG, Basel } \\
\text { www.karger.com/cpb }\end{array}$
\end{tabular} \\ Xu et al.: Effects of Propofol and Sevoflurane on Liver Ischemic Reperfusio Injury}

Both the treatments had no effect on the expression of AKT, Bad and p38. Conclusion: Both propofol and sevoflurane can protect the liver from ischemia/reperfusion injury by modulating the inflammatory responses reducing oxidative stress and liver apoptosis.

(C) 2016 The Author(s)

Published by S. Karger AG, Basel

\section{Introduction}

Liver damage is induced by a variety of pathological ways like liver ischemia/reperfusion and liver fibrosis $[1,2]$. Liver ischemia/reperfusion injury is a phenomenon in which cellular damage is induced by hypoxia following the return of blood flow and restoration of oxygen delivery after transplantation surgery, tissue resections, hemorrhagic shock and so forth $[3,4]$. Therefore, it is a crucial consideration in the management of hepatobiliary surgery, especially liver resection and liver transplantation surgery, which remains a major cause of graft dysfunction or nonfunction and results in a high mortality [5]. Liver I/R injury usually occurs during traumatic shock or hepatic surgery. It affects the liver function and also significantly increases the risk to the circulatory system and respiratory system. All these issues make liver ischemia/reperfusion a highly important clinical problem to be studied and solved [6].

To date, various mechanisms that interact with each other in the complex pathophysiological processes of hepatic ischemia reperfusion have been explored [7]. It has been demonstrated that liver ischemia/reperfusion involves a large number of different processes, include the pathogenesis of adenosine triphosphate (ATP) depletion, lactate accumulation, and acidosis during ischemia and the production of free radicals such as reactive oxygen, lipid and nitrogen species, calcium overload, and neutrophil activation [8]. Resently, increased autophagic flux was found to contribute to liver injury during I/R in vivo. However, the precise mechanisms of I/R-induced liver injury have not been elucidated clearly [9-11]. Propofol is widely used in clinical anesthesia, and it has been reported to have a protective effect in ischemia/reperfusion injury in the heart $[12,13]$, brain and lower limbs [14-16]. Similarly, in liver transplantation, propofol is extensively used because its metabolism is not greatly affected by liver failure [17]. Volatile anesthetic agents have been shown to preserve hepatic blood flow and cell function after ischemia of the liver. Sevoflurane, a new inhalation anesthetic, has recently been developed and is now frequently used [18]. Sevoflurane is known to act as a bronchodilator by directly relaxing the bronchial smooth muscle through a reduction in $\mathrm{Ca} 2+$ concentration and perturbation of calcium homeostasis, similarly to other inhalation anesthetics [19-21].

Previous studies comparing sevoflurane and propofol have produced variable results [22]. It was reported that the use of propofol for total intravenous anesthesia in OLV might be safer for patients than the use of sevoflurane and is expected to have a lower risk of direct damage from anesthetic metabolites $[23,24]$. However, sevoflurane may offer better protection against reperfusion injury after one-lung ventilation in thoracic surgery [25].

Consequently, the aim of this study was to explore whether propofol and sevoflurane have protective effects in hepatic ischemia reperfusion in a rat model, and subsequently the mechanisms through which they play their roles to provide basic evidence for their clinical use.

\section{Methods and Materials}

\section{Animals}

Male Sprague-Dawley rats weighing 250-280 g were obtained from the Vital River Company. This study was approved by the Institutional Committee on Animal Care at Qilu Hospital of Shandong University. The animals were fed a standard laboratory diet and were housed under SPF conditions, according to the institutional guidelines. 


\section{Cellular Physiology Cell Physiol Biochem 2016;38:1631-1642

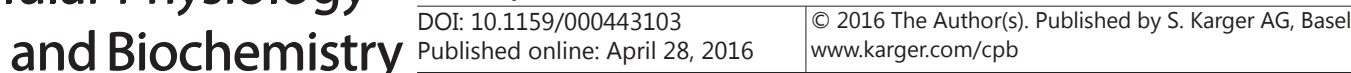 \\ Xu et al.: Effects of Propofol and Sevoflurane on Liver Ischemic Reperfusio Injury}

Surgical procedure

Animals were randomly divided into 4 groups: the sham operation (Sham) group; hepatic ischemia/ reperfusion (I/R) group; propofol treatment group; and sevoflurane treatment group.

Intraperitoneal injection of $1 \%$ pentobarbital sodium $(40 \mathrm{mg} / \mathrm{kg}$ ) was used for anesthesia. The liver was separated from the surrounding ligaments, a midline laparotomy was performed with minimal dissection, and the portal vein and the common hepatic artery were isolated and prepared for occlusion. Hepatic ischemia (70\%) was created for $60 \mathrm{~min}$ by clamping the portal vein, hepatic artery, and bile duct of the left and median; then, reperfusion was initiated by the removal of the clamp for $120 \mathrm{~min}$. Afterward, the tissue and blood samples were collected. Parts of the hepatic tissue samples were stored at $-80^{\circ} \mathrm{C}$, and the others were placed in $10 \%$ formaldehyde. Injectors $(5 \mathrm{~mL}$ ) were used to collect blood samples from the rat vena cava and centrifuged at $4024 \mathrm{G} / \mathrm{min}$ for $5 \mathrm{~min}$. Serum was stored at $-80^{\circ} \mathrm{C}$ until further examination.

Rats in the sevoflurane group were administered 3\% (2 L/min) sevoflurane (AbbVie Inc., North Chicago, IL, USA) by inhalation, and rats in the propofol group were infused with $1 \%$ propofol at $500 \mu \mathrm{g} \cdot \mathrm{kg}-1^{\prime} \cdot \mathrm{min}-1$ (AstraZeneca Plc., London, UK) throughout the surgical process [26].

\section{ELISA assay}

Enzyme-linked immunosorbent assay (ELISA) analysis was performed to detect the concentrations and levels of the inflammatory mediators (TNF- $\alpha$, IL-1, IL-10 and IL-6) in the serum using ELISA kits (Biosource International Inc., USA). Meanwhile, the levels of oxidative stress biomarkers MDA and NO and the antioxidant marker SOD in liver tissue were evaluated using specific detection kits (Beyotime Biotechnology, Shanghai, China) for rats according to the manufacturer's protocols.

Terminal deoxynucleotidyl transferase-mediated dUTP nick-end labeling (TUNEL) assay

Paraffin sections ( $4 \mu \mathrm{m}$ in thickness) were deparaffinized in toluene and then dehydrated in a graded series of ethanol solutions. An in situ Cell Death Detection kit (Roche Applied Science, IN, USA) was used to detect apoptosis in the liver tissues according to the manufacturer's instructions. Quantitative analysis is presented as a percentage of TUNEL-positive hepatocyte nuclei per total nuclei in each experimental group.

\section{Histology study}

Liver tissues were collected and fixed in 10\% formalin for more than 24 hours, embedded and sectioned at $4 \mu \mathrm{m}$ thickness. Subsequently, the sections were stained with hematoxylin-eosin. Inflammation and tissue damage were evaluated in histopathological analysis by light microscopy. Suzuki classification was performed, consisting of 3 parameters of hepatic ischemia reperfusion injury: sinusoidal congestion, vacuolization of hepatocyte cytoplasm, and parenchymal necrosis, which were graded numerically as follows: congestion: $0=$ none, $1=$ minimal, $2=\operatorname{mild}, 3=$ moderate, and $4=$ severe. The same criteria were adopted in the gradation of the vacuolization and necrosis.

\section{Immunohistochemistry}

Sections were heated with $10 \mathrm{mmol} / \mathrm{L}$ citrate buffer $(\mathrm{pH} 6.0)$ at a temperature of $92-98^{\circ} \mathrm{C}$ and maintained for $10 \mathrm{~min}$, then left to return room temperature naturally. Endogenous peroxidase activity was blocked by incubating the sections in $2 \%(\mathrm{v} / \mathrm{v})$ hydrogen peroxidase diluted in $50 \%(\mathrm{v} / \mathrm{v})$ methanol for $30 \mathrm{~min}$. Afterward, the specimens were blocked with $5 \%$ goat serum for $15 \mathrm{~min}$, followed by incubation at $4^{\circ} \mathrm{C}$ overnight with anti-p-AKT and p-p38 primary antibody (diluted 1:250 with $5 \%$ goat serum). Sections were incubated with HRP-conjugated secondary antibody for $1 \mathrm{~h}$. Peroxidation activity was visualized via incubation with a peroxidase substrate solution, DAB (Beyotime Biotechnology, Beijing, China). All sections were counterstained with hematoxylin.

\section{Western blot}

Frozen liver tissues were homogenized in RIPA lysis buffer in the presence of $1 \%(\mathrm{v} / \mathrm{w})$ protease inhibitor cocktail (Pierce Biotechnology, Rockford, IL). The samples were shaken at $4^{\circ} \mathrm{C}$ for $1 \mathrm{~h}$ followed by centrifugation at $40000 \times \mathrm{g}$ at $4^{\circ} \mathrm{C}$ for another $1 \mathrm{~h}$. Protein concentration was determined by the Bradford method using bovine serum albumin (BSA) as the standard [4]. Then, $40 \mu \mathrm{g}$ protein was subjected to sodium dodecyl sulfate-polyacrylamide gel electrophoresis (Bio-Rad Laboratories, Hercules, CA) and blotted onto nitrocellulose membranes. After incubation with the specific primary antibodies anti-p65, anti-p -p-65, 


\section{Cellular Physiology Cell Physiol Biochem 2016;38:1631-1642 \begin{tabular}{l|l} 
and Biochemistry Published online: April 28, 2016 & $\begin{array}{l}\text { D } 2016 \text { The Author(s). Published by S. Karger AG, Basel } \\
\text { www.karger.com/cpb }\end{array}$
\end{tabular} \\ Xu et al.: Effects of Propofol and Sevoflurane on Liver Ischemic Reperfusio Injury}

anti-IKBa, anti-bcl-2, anti-bcl-xl, anti-bax, anti-bak, anti-cytochrome c, anti-cleaved caspase 9, anti-cleaved caspase 3, anti-AKT, anti-p-AKT, anti-p38, anti-p-P38, anti-BAD, anti-p-BAD, and anti-GAPDH (Cell Signaling Technology, Danvers, MA) in blocking solution overnight at $4{ }^{\circ} \mathrm{C}$, the blots were probed with a secondary horseradish peroxidase (HRP)-conjugated antibody (Santa Cruz, CA, USA) and developed with enhanced chemiluminescence reagents. The relative amount of the target protein was normalized to GAPDH and analyzed using a Gel Pro Analyzer (Media Cybernetics, Silver Spring, MD, USA).

\section{Quantitative real-time PCR}

Total RNA was extracted from liver tissue using a HiPure Liquid RNA/miRNA Kit (Invitrogen, Carlsbad, CA). CDNA was generated with the stem-loop reverse transcript primer and Moloney murine leukemia virus reverse transcriptase (Promega, Madison, WI, USA), followed by qPCR on an iQ5 real-time PCR detection system (Bio-Rad) with SYBR Premix EX Taq (TaKaRa, Otsu, Shiga, Japan). $\beta$-Actin was used as an endogenous control. All measurements were performed in triplicate. The real-time PCR data were analyzed using the $\triangle \Delta \mathrm{CT}$ method. The primers used were as follows:

IL-6 forward: 5' TAGTCCTTCCTACCCCAATTTCC 3'

reverse: 5' TTGGTCCTTAGCCACTCCTTC 3'

IL-10forward: 5' GCTGCCGTCATTTTCTGC 3',

reverse: 5' TCTCACTGGCCCGTCATC 3'

IL-1 forward: 5' GGATGATGACGACCTGCTAG 3'

reverse: 5'GGCTTATGTTCTGTCCATTGAG 3'

TNF- $\alpha$ forward: 5' CCCTCACACTCAGATCATCTTCT 3'

reverse: 5' GCTACGACGTGGGCTACAG 3'

$\beta$-actin forward: 5' TCACCAACTGGGACG 3'

reverse: 5' GCATACAGGGACAACA 3'

Statistical analysis

The data are reported as the mean \pm S.D. of at least three independent experiments with the double-sided Student's t test. A p value of less than 0.05 was considered significant $\left({ }^{*} \mathrm{p}<0.05, \# \mathrm{p}<0.05\right.$, $\& \mathrm{p}<0.05)$.

\section{Results}

Propofol and sevoflurane treatment protected the liver from ischemic injury

Histological evaluation of the damage in the liver was performed by hematoxylin-eosin staining. Pathological changes in the IR group, indicated by Suzuki's score, revealed the severe damage induced by IR; similarly, propofol and sevoflurane depressed the damage indicated by Suzuki's score(Fig. 1 A-E). To assess liver injury, we used several markers, including AST (aspartate aminotransferase), ALT (alanine aminotransferase), and LDH (lactate dehydrogenase), released into the serum. These enzyme levels in the I/R group were increased significantly, while both propofol and sevoflurane decreased the leakage of all three enzymes (Fig. 1 F-H).

Propofol and sevoflurane treatment attenuated inflammation by influencing $N F \kappa B$ expression

Inflammatory cytokines, such as TNF- $\alpha$, IL-1, IL-6 and IL-10, play key roles in the pathophysiology of hepatic I/R injury. To determine whether propofol and sevoflurane reduce the levels of these cytokines, we used ELISA and QRT-PCR to measure the level and the mRNA expression in the liver tissue. Propofol and sevoflurane both reduced the release and mRNA expression of TNF- $\alpha$, IL-1, and IL-6 and increased IL-10 (Fig. 2 A-D, Fig. 2 E-H). However, propofol showed significantly lower IL-1 and higher TNF- $\alpha$ release compared with sevoflurane (Fig. 2 A-B). Subsequently, the expression of NFKB was detected by western blot to investigate whether the alteration of inflammatory cytokine release is regulated by $\mathrm{NF} \kappa \mathrm{B}$. As expected, the elevated phosphorylation of P65 induced by I/R is suppressed by propofol and sevoflurane treatment. In contrast, the expression of I $\mathrm{B} \alpha$ was upregulated KARGER 


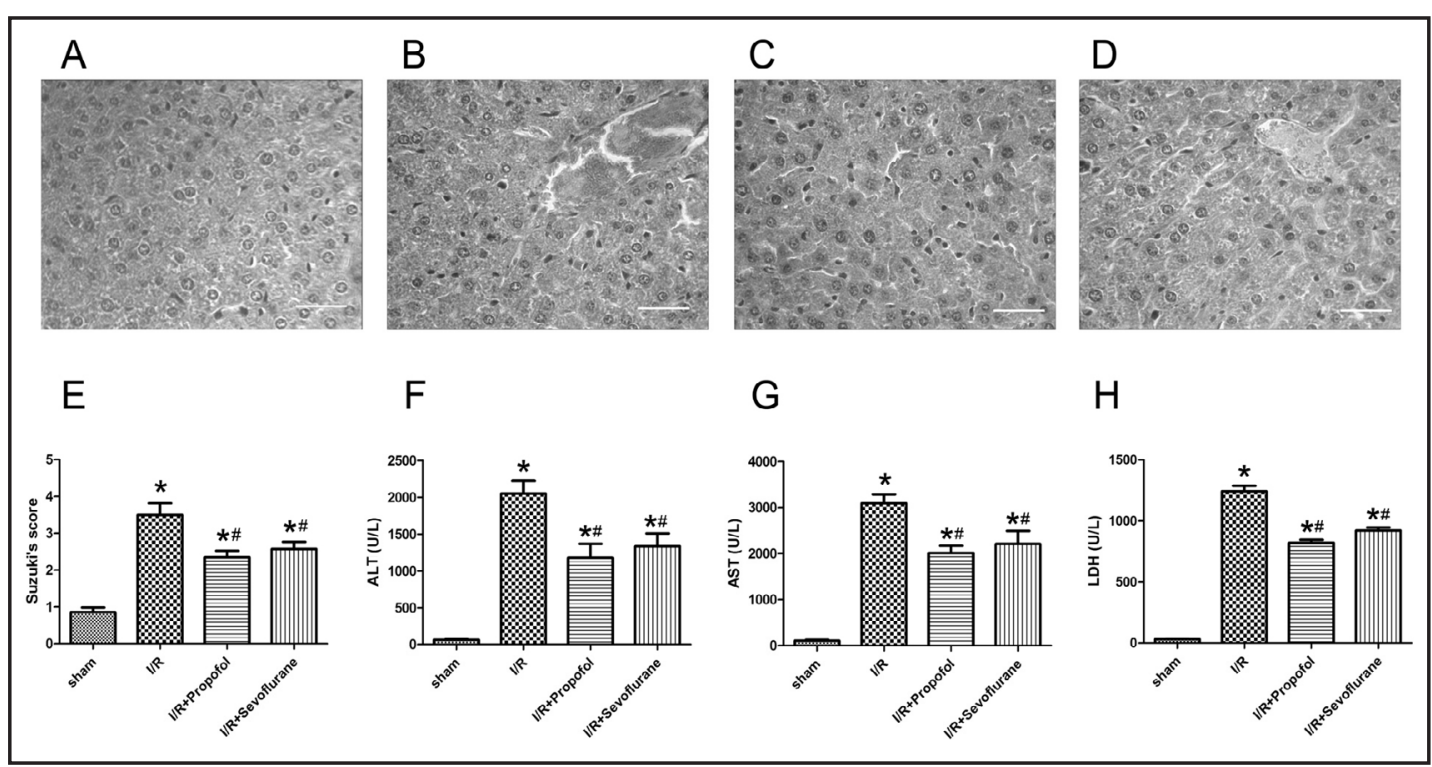

Fig. 1. The effects of propofol and sevoflurane on I/R-induced liver injury. (A-D) Hematoxylin-eosin staining. Liver sections were collected for HE staining after $60 \mathrm{~min}$ of ischemia and $120 \mathrm{~min}$ of reperfusion (200× magnification). (E) Suzuki's scores for the tissues. (F and G) The serum levels of alanine aminotransferase (ALT) and aspartate aminotransferase (AST). (H) LDH activities. At least six rats were included in each group. The results are expressed as the mean $\pm S D$. $* P<0.05$ versus sham, $\# \mathrm{P}<0.05$ versus $I / R(n=6)$.

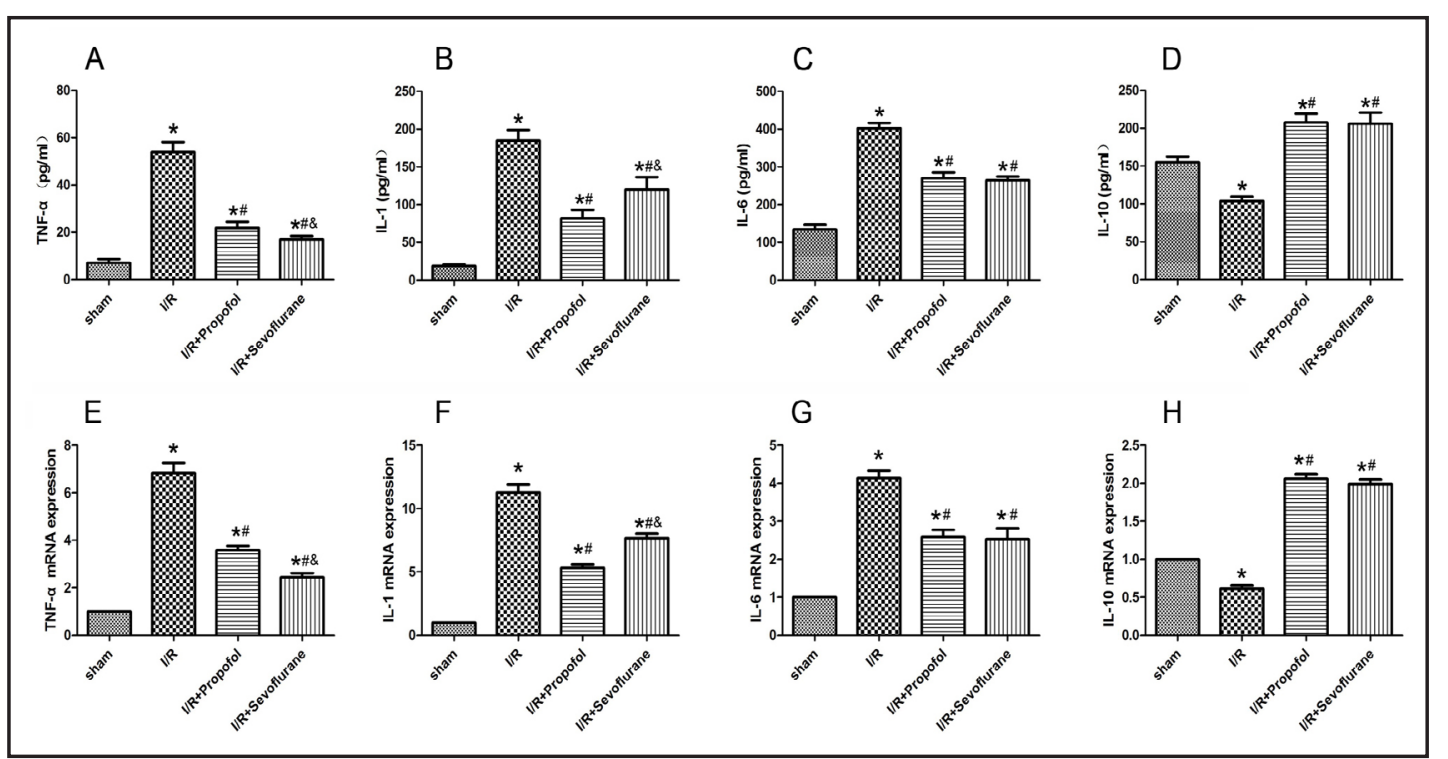

Fig. 2. Effects of propofol and sevoflurane on inflammatory mediators including TNF- $\alpha$, IL-1, IL-6 and IL-10. (A-D) TNF- $\alpha$, IL-1, IL- 6 and IL-10 levels in the serum were determined by ELISA. ${ }^{*} \mathrm{P}<0.05$ versus sham. (E-H) The mRNA expression levels of TNF- $\alpha$, IL-1, IL- 6 and IL-10 in liver tissues were determined by real-time PCR in each group. ${ }^{*} \mathrm{P}<0.05$ vs. sham, $\# \mathrm{P}<0.05$ vs. I/R, $\& \mathrm{P}<0.05$ vs. $\mathrm{I} / \mathrm{R}+$ propofol $(\mathrm{n}=6)$.

by propofol and sevoflurane (Fig. 3 A-D). Propofol exhibited a stronger inhibitory effect on NFKB expression.

Propofol and sevoflurane treatments attenuated oxidative stress

The MDA, SOD and NO levels were assayed to evaluate the effect of propofol and sevoflurane on oxidative stress. The levels of MDA and NO were significantly increased 


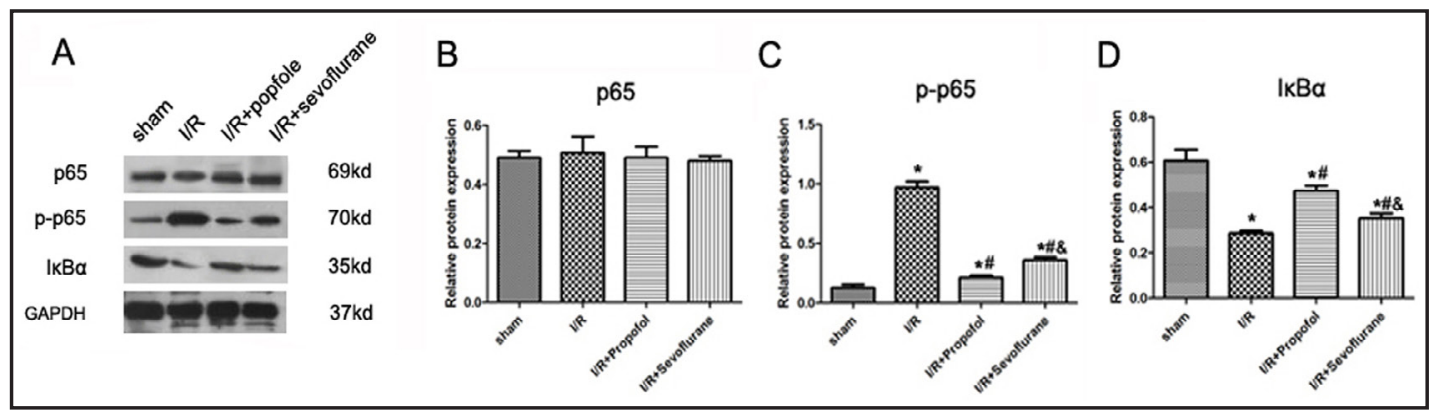

Fig. 3. Effects of propofol and sevoflurane on p-p65 and IкB $\alpha$ expression . (A) Representative western blots

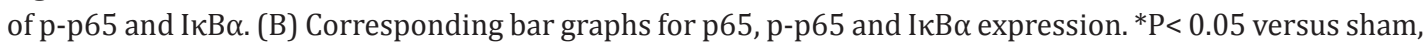
$\# P<0.05$ versus $I / R, \& P<0.05$ versus $I / R+$ propofol $(n=6)$.

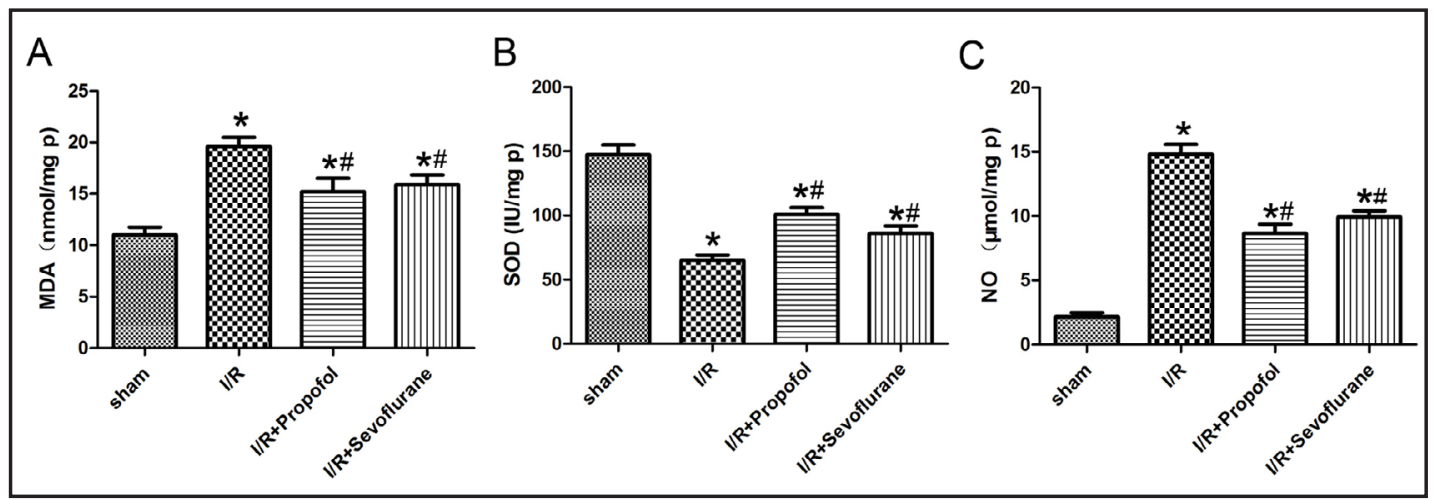

Fig. 4. Effects of propofol and sevoflurane on SOD, MDA and NO production. (A and B) MDA content and SOD activity in rat liver were determined after I/R injury in each group. (C) NO production was measured using Griess Reagent in liver tissue collected from I/R injured rats. The results are expressed as the mean \pm SD. ${ }^{*} \mathrm{P}<0.05$ versus sham, $\# \mathrm{P}<0.05$ versus $\mathrm{I} / \mathrm{R}(\mathrm{n}=6)$.

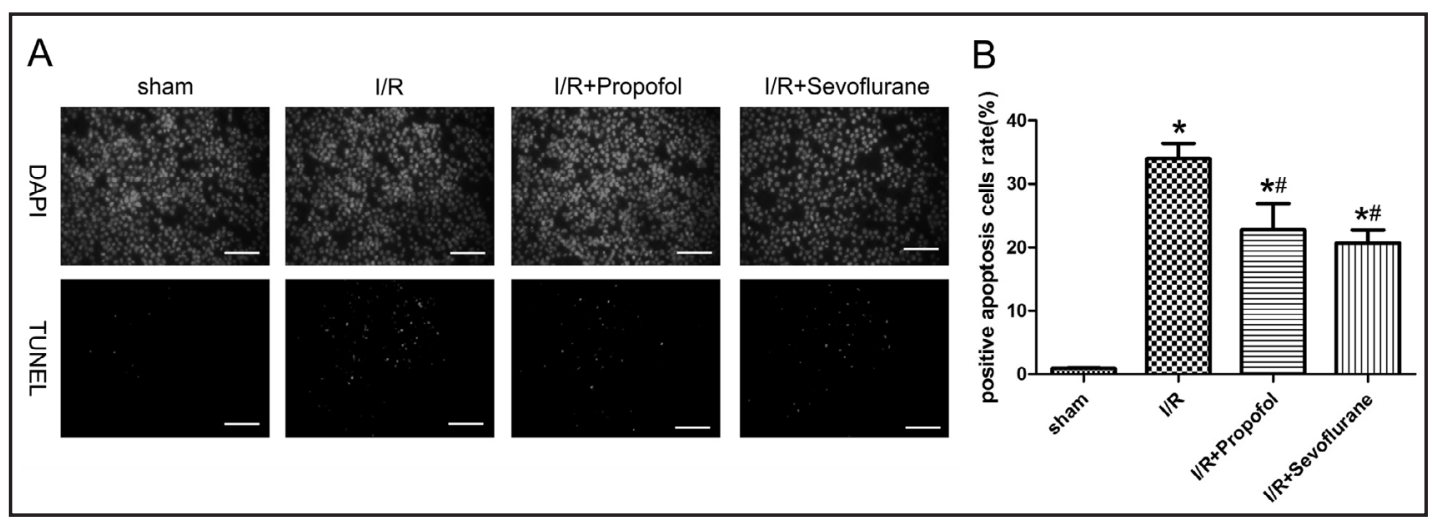

Fig. 5. Effects of propofol and sevoflurane on hepatocyte apoptosis. (A) Liver sections were collected for TUNEL staining after $60 \mathrm{~min}$ of ischemia and $120 \mathrm{~min}$ of reperfusion (magnification, $\times 200$ ). (B) Positive apoptosis cell rate in sham, I/R, I/R+ propofol and I/R+ sevoflurane groups. ${ }^{*} \mathrm{P}<0.05$ vs. sham, $\# \mathrm{P}<0.05$ vs. I/R $(n=6)$.

during ischemia reperfusion and recovered by propofol and sevoflurane treatment. The level of SOD was decreased in the propofol and sevoflurane treatment groups compared with the I/R group(Fig. 4 A-C) .

Propofol and sevoflurane treatment induced apoptosis through a mitochondrial pathway

The TUNEL assay was used to detect apoptosis in the ischemic liver. The apoptotic rate in the I/R group was significantly increased, and propofol and sevoflurane both attenuated 
Fig. 6. Effects of propofol and sevoflurane on Bcl-2 family, AKT and p38 MAPK signaling pathways. Proteins in liver tissues were determined by western blot analysis.

(A) Representative western blots of Bcl2, Bcl-xl, Bax, Bak, cytochrome C, caspase 9 and caspase 3. (B) Corresponding bar graphs for Bcl-2, Bcl-xl, Bax and Bak expression. (C) Corresponding bar graphs for cytochrome $\mathrm{C}$, caspase 9 and caspase 3 expression. (D) Representative western blots of p-Akt, p-Bad and p-p38. (E) Corresponding bar graphs for AKT and p-Akt. (F) Corresponding bar graphs for Bad and p-Bad. (G) Corresponding bar graphs for p38 and p-p38. ${ }^{*} \mathrm{P}<0.05$ versus sham, $\# \mathrm{P}<0.05$ versus $\mathrm{I} / \mathrm{R}$. $\& \mathrm{P}<0.05$ versus $\mathrm{I} / \mathrm{R}+$ propofol $(n=6)$.

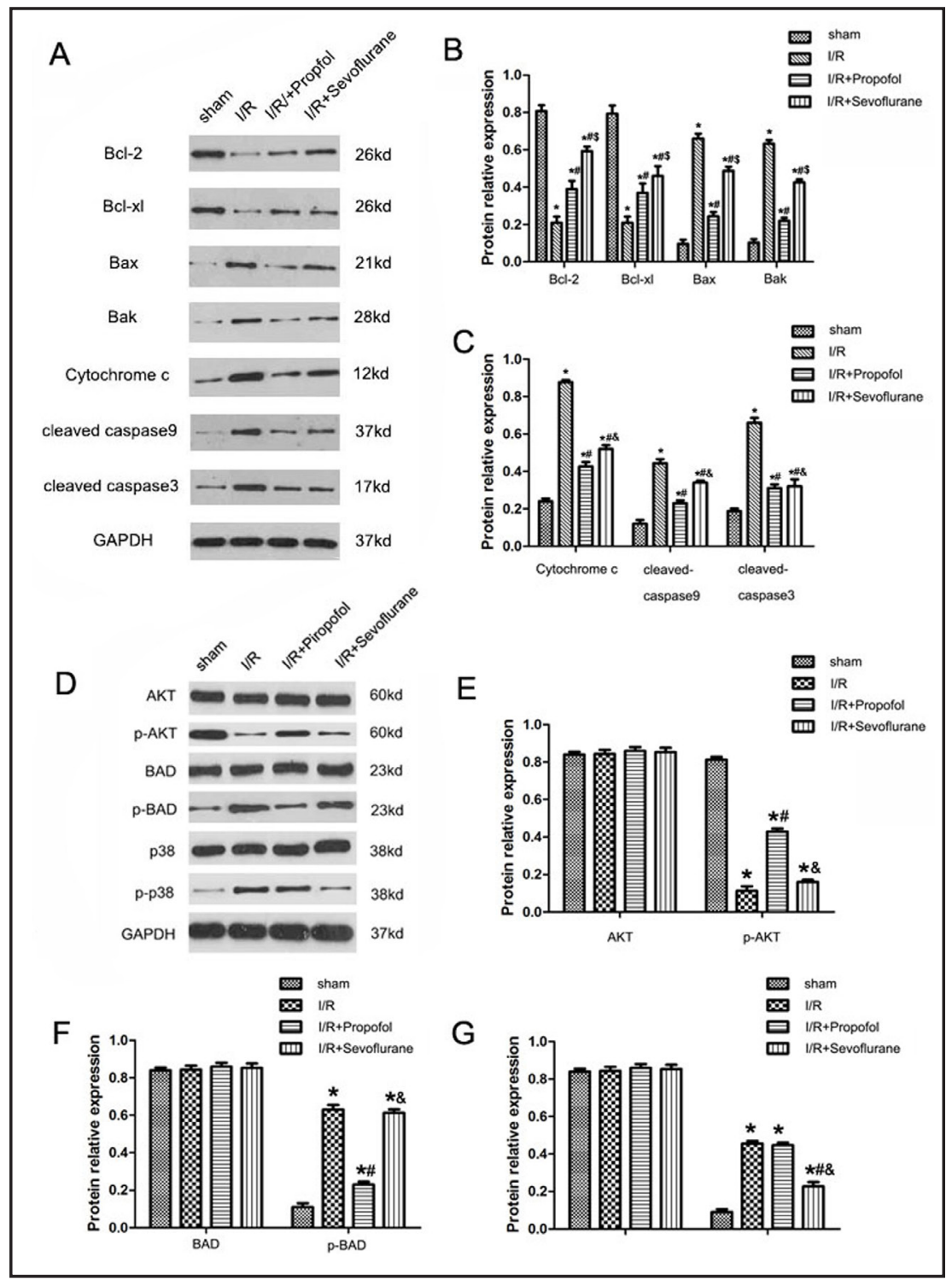

the apoptosis (Fig. 5 A,B). Furtherly, western blotting was used to explore the mechanism through which propofol and sevoflurane performed their antiapoptotic roles. Propofol and sevoflurane inhibited the downregulation of antiapoptotic proteins such as bcl-2 and bcl-xl while decreasing the upregulation of proapoptotic proteins such as bak and bax in ischemic liver injury (Fig. 6 A-B), ultimately downregulating the expression of cytochrome c and caspase protein (cleaved-caspase 9, cleaved-caspase 3), which induce apoptosis in liver tissue (Fig. 6 A,C). In addition, we found that sevoflurane had a better effect in regulating the expression of the proteins mentioned above, except for caspase 3. Moreover, we investigated the total expression and phosphorylation of AKT, BAD and p-38, which play crucial roles in ischemia/reperfusion-induced apoptosis. Propofol enhanced the phosphorylation of AKT while inhibited the phosphorylation of BAD. Sevoflurane significantly reduced the phosphorylation of p-38 induced in liver ischemia reperfusion, while no changes were found in the total expression or phosphorylation of AKT and BAD (Fig. 6 D-G). Immunohistochemical detection of p-AKT and p-p38 in the liver tissue was consistent with previous findings. The phosphorylation of AKT was elevated in propofol treatment, while the phosphorylation of p38 was inhibited in sevoflurane treatment (Fig. 7 A-B).

\section{KARGER}




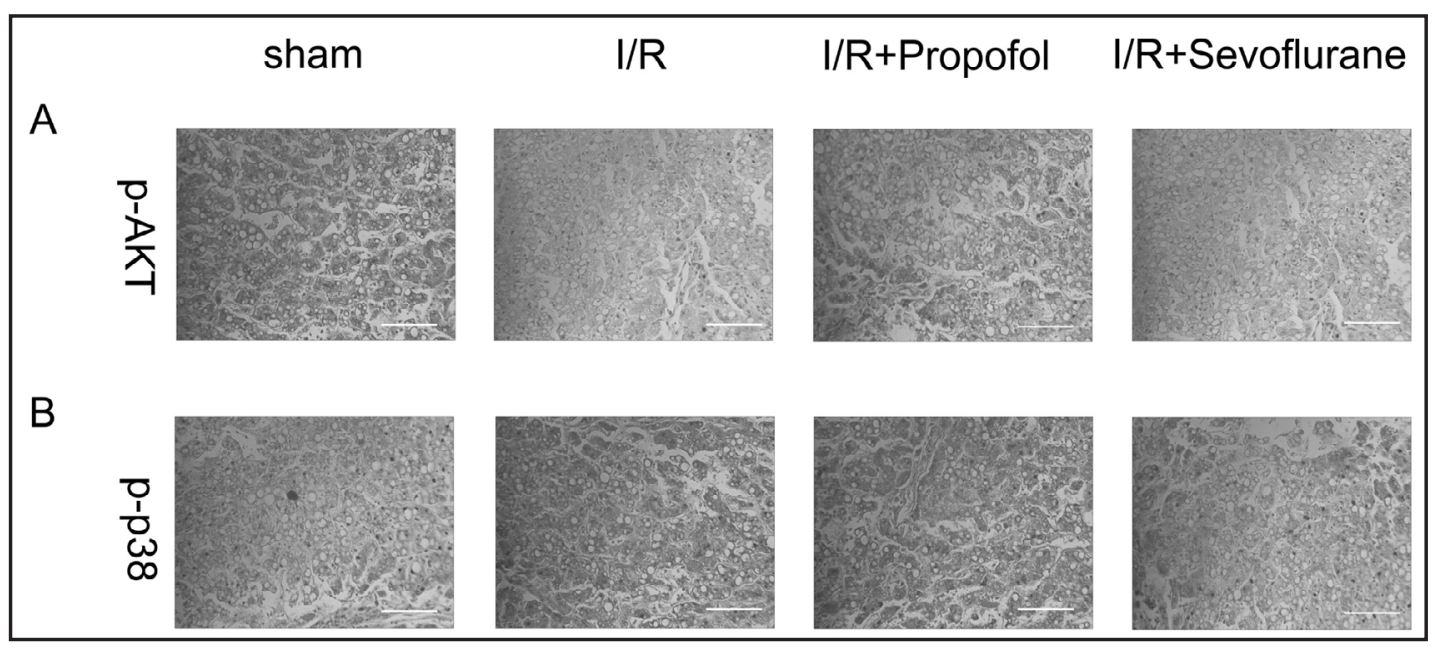

Fig. 7. Propofol and sevoflurane treatment influenced the expression of p-Akt and p-p38 proteins in hepatic I/R injured rats. (A and B) Immunohistochemical staining for p-Akt and p-p38 was performed on liver sections from rats that had undergone $60 \mathrm{~min}$ of ischemia followed by $120 \mathrm{~min}$ (magnification, $\times 200)(\mathrm{n}=6)$.

\section{Discussion}

The main cause of liver I/R injury is surgery. The mechanism includes long-term or severe ischemia, with insufficient blood supply for the liver, and I/R caused by other physiological or biochemical factors [27]. Accordingly, the development of methods to prevent biochemical factor-mediated I/R injury remains an urgent issue to be solved [28].

Serum AST, ALT and LDH, as important indicators of liver injury, along with histologic examination by hematoxylin-eosin staining, objectively indicate the extent of ischemia/ reperfusion injury in the liver. All the results revealed the protective effect of propofol and sevoflurane on liver ischemia/reperfusion.

It is well known that the liver damage after hepatic I/R is associated with an inflammatory response [29]. The reduced release of some inflammatory cytokines can protect from hepatic I/R injury. Propofol has been reported to be associated with lower IL (interleukin)-6, IL$1 \beta$ and TNF- $\alpha$ expression $[30,31]$ and improves IL-10 secretion in traumatic inflammatory responses. Sevoflurane could also reverse the IR-induced decrease in IL-10 expression and inhibit IL-1 $\beta$, IL- 6 and TNF- $\alpha$ expression in cerebral focal ischemia-reperfusion damage in a rat model $[32,33]$. These changes in expression mediate cell death and can further enhance the pro-inflammatory response. Our study revealed that propofol and sevoflurane exhibited lower IL-6, IL-1 and TNF- $\alpha$ expression, while clearly increased IL-10 expression. Interestingly, the expression of TNF- $\alpha$ in the sevoflurane treatment group is lower than in the propofol group, in contrast, IL-1 expression in the propofol was lower . Our findings indicated that propofol and sevoflurane might protect from liver ischemia reperfusion by influencing the expression of some inflammatory cytokines.

$\mathrm{NF} \kappa \mathrm{B}$ is a crucial transcriptional factor involved in inflammation through the protranscriptional regulation of several cytokines, for instance, IL-1, IL-6, IL-10 and TNF- $\alpha$, and p-65 plays a key role in the NFKB family [34-36]. To determine whether cytokine expression was regulated by NFKB pathway, qPCR was used to assess the mRNA expression. The results confirmed our hypothesis that propofol and sevoflurane inhibited the phosphorylation of $\mathrm{NF} \kappa \mathrm{B}$, with the consequent alteration of IL-1, IL-6, IL-10 and TNF- $\alpha$.

Under normal conditions, reactive oxygen species (ROS) in the liver are constantly produced as byproducts of mitochondrial respiration. When the cellular levels of ROS exceed the neutralizing capabilities of cellular nonenzymatic and enzymatic antioxidants, oxidative stress occurs. ROS plays an important role in the pathogenesis of various hepatic disorders, including I/R injury [37]. Substantial evidence has suggested that the initial production of 


\section{Cellular Physiology Cell Physiol Biochem 2016;38:1631-1642 \\ \begin{tabular}{c|c} 
DOI: 10.1159/000443103 & Ond 2016 The Author(s). Published by S. Karger AG, Basel \\
www.karger.com/cpb
\end{tabular} \\ Xu et al.: Effects of Propofol and Sevoflurane on Liver Ischemic Reperfusio Injury}

ROS and the subsequent activation of several molecular signaling cascades lead to cellular damage and an imbalance between pro- and anti-inflammatory responses [38, 39], which is consistent with our previous findings. A well-known mechanism of cell death induced by extracellular ROS is lipid peroxidation, a free radical-mediated process that leads very rapidly to liver cell death. Our research detected a significantly lower MDA level but a higher SOD level in both the propofol and sevoflurane treatment groups, indicating an antioxidant action in the ischemic liver tissue. A low concentration of NO may serve to promote cell survival and protect the liver against I/R injury.

Hepatic cell death occurs due to both necrosis and apoptosis [40]. Apoptosis is a central mechanism of cell death following reperfusion of the ischemic liver. To further demonstrate the mechanisms of liver protection against I/R injury, cell apoptosis was subsequently evaluated in ischemic liver tissue. TUNEL assay results indicated that propofol and sevoflurane can both attenuate apoptosis in ischemic liver tissue. The mechanism of apoptosis is highly complex. Increasing mitochondrial permeability is a major cause of apoptosis during hepatic ischemia/reperfusion injury. Oxidative stress caused by ROS generation can promote mitochondrial transmembrane potential (MPT), which in turn further elevates the oxidative stress level [41]. We have demonstrated that both propofol and sevoflurane influence the oxidative stress, which led to the hypothesis that propofol and sevoflurane play an antiapoptotic role through regulating mitochondrial permeability. The Bcl-2 family proteins are implicated in the regulation of the mitochondria-mediated apoptosis pathway [42].

The mitochondrial permeability is controlled by Bcl-2 proteins, either promoting or inhibiting apoptosis directly through mitochondrial permeability transition pores. As in this study, once the expression of pro-apoptotic proteins such as Bax and Bak or of antiapoptotic proteins such as Bcl-2 and Bcl-xl was altered, cytochrome c would be released from the intermembrane space. As a component of the mitochondrial electron transfer chain, cytochrome c could initiate caspase activation, including caspase 9 and caspase 3, ultimately induced apoptosis in hepatic injury [43]. A number of studies reported that p38 MAPK and AKT were activated by ROS and cytokines [44-46]. The PI3K/Akt and p38 MAPK pathway exists extensively in cells and is involved in the regulation of a series of physiological activities such as cell apoptosis. Both propofol and sevoflurane were reported to regulate AKT and p38 expression levels [47-49]; however, this phenomenon was not observed in our study. As expected, propofol increased the phosphorylation of AKT but decreased the phosphorylation of Bad, while no changes were detected in the expression or phosphorylation of $\mathrm{p} 38$. Interestingly, in the sevoflurane treatment group, only p-38 phosphorylation was decreased, while the others remained unchanged.

In conclusion, propofol and sevoflurane both protect the liver from ischemia/ reperfusion injury through modulation of several vital pathophysiological processes such as altered cytokine release; oxidative stress with changed ROS generation; and apoptosis. These processes are interrelated and throw light on the precise mechanism of protection.. Further research in this field is warranted which will provide the necessary information for the clinical use of propofol and sevoflurane.

\section{Disclosure Statement}

No potential conflicts of interest were disclosed.

\section{Reference}

1 Hochhauser E, Lahat E, Sultan M, Pappo O, Waldman M, Sarne Y, Shainberg A, Gutman M, Safran M, Ari ZB: Ultra low dose delta 9-tetrahydrocannabinol protects mouse liver from ischemia reperfusion injury. Cell Physiol Biochem 2015;36:1971-1981. 


\section{Cellular Physiology Cell Physiol Biochem 2016;38:1631-1642 and Biochemistry Published online: April 28, $2016 \quad$\begin{tabular}{l|l} 
DOI: 10.1159/000443103 & $\begin{array}{l}\text { C } 2016 \text { The Author(s). Published by S. Karger AG, Basel } \\
\text { www.karger.com/cpb }\end{array}$
\end{tabular} \\ Xu et al.: Effects of Propofol and Sevoflurane on Liver Ischemic Reperfusio Injury}

2 Zhang X, Tan Z, Wang Y, Tang J, Jiang R, Hou J, Zhuo H, Wang X, Ji J, Qin X, Sun B: Ptpro-associated hepatic stellate cell activation plays a critical role in liver fibrosis. Cell Physiol Biochem 2015;35:885-898.

3 Li C, Jackson RM: Reactive species mechanisms of cellular hypoxia-reoxygenation injury. Am J Physiol Cell Physiol 2002;282:C227-241.

4 Jaeschke H: Molecular mechanisms of hepatic ischemia-reperfusion injury and preconditioning. Am J Physiol Gastrointest Liver Physiol 2003;284:G15-26.

5 Montalvo-Jave EE, Pina E, Montalvo-Arenas C, Urrutia R, Benavente-Chenhalls L, Pena-Sanchez J, Geller DA: Role of ischemic preconditioning in liver surgery and hepatic transplantation. J Gastrointest Surg 2009;13:2074-2083.

6 Wang Y, Shen J, Xiong X, Xu Y, Zhang H, Huang C, Tian Y, Jiao C, Wang X, Li X: Remote ischemic preconditioning protects against liver ischemia-reperfusion injury via heme oxygenase-1-induced autophagy. PLoS One 2014;9:e98834.

$7 \quad$ Kang JW, Cho HI, Lee SM: Melatonin inhibits mtor-dependent autophagy during liver ischemia/reperfusion. Cell Physiol Biochem 2014;33:23-36.

8 Grossini E, Pollesello P, Bellofatto K, Sigaudo L, Farruggio S, Origlia V, Mombello C, Mary DA, Valente G, Vacca G: Protective effects elicited by levosimendan against liver ischemia/reperfusion injury in anesthetized rats. Liver Transpl 2014;20:361-375.

9 Schulz R, Kelm M, Heusch G: Nitric oxide in myocardial ischemia/reperfusion injury. Cardiovasc Res 2004;61:402-413.

10 Ren G, Dewald O, Frangogiannis NG: Inflammatory mechanisms in myocardial infarction. Curr Drug Targets Inflamm Allergy 2003;2:242-256.

11 Kihara F, Inoue Y, Arima I, Ono M, Masumoto H: [case of recklinghausen's disease presenting as acute porphyria in the terminal stage]. Naika 1966;18:381-387.

12 Kokita N, Hara A, Abiko Y, Arakawa J, Hashizume H, Namiki A: Propofol improves functional and metabolic recovery in ischemic reperfused isolated rat hearts. Anesth Analg 1998;86:252-258.

13 Javadov SA, Lim KH, Kerr PM, Suleiman MS, Angelini GD, Halestrap AP: Protection of hearts from reperfusion injury by propofol is associated with inhibition of the mitochondrial permeability transition. Cardiovasc Res 2000;45:360-369.

14 Aldemir O, Celebi H, Cevik C, Duzgun E: The effects of propofol or halothane on free radical production after tourniquet induced ischaemia-reperfusion injury during knee arthroplasty. Acta Anaesthesiol Scand 2001;45:1221-1225.

15 De La Cruz JP, Villalobos MA, Sedeno G, Sanchez De La Cuesta F: Effect of propofol on oxidative stress in an in vitro model of anoxia-reoxygenation in the rat brain. Brain Res 1998;800:136-144.

16 Yamaguchi S, Hamaguchi S, Mishio M, Okuda Y, Kitajima T: Propofol prevents lipid peroxidation following transient forebrain ischemia in gerbils. Can J Anaesth 2000;47:1025-1030.

17 Takizawa D, Sato E, Hiraoka H, Tomioka A, Yamamoto K, Horiuchi R, Goto F: Changes in apparent systemic clearance of propofol during transplantation of living related donor liver. Br J Anaesth 2005;95:643-647.

18 Kim JW, Kim JD, Yu SB, Ryu SJ: Comparison of hepatic and renal function between inhalation anesthesia with sevoflurane and remifentanil and total intravenous anesthesia with propofol and remifentanil for thyroidectomy. Korean J Anesthesiol 2013;64:112-116.

19 Dikmen Y, Eminoglu E, Salihoglu Z, Demiroluk S: Pulmonary mechanics during isoflurane, sevoflurane and desflurane anaesthesia. Anaesthesia 2003;58:745-748.

20 Goff MJ, Arain SR, Ficke DJ, Uhrich TD, Ebert TJ: Absence of bronchodilation during desflurane anesthesia: A comparison to sevoflurane and thiopental. Anesthesiology 2000;93:404-408.

21 Puglisi F, Crovace A, Staffieri F, Capuano P, Carravetta G, De Fazio M, Lograno G, Lacitignola L, Troilo VL, Martines G, Chiumarulo C, Memeo V: Comparison of hemodynamic and respiratory effects of propofol and sevoflurane during carbon dioxide pneumoperitoneum in a swine model. Chir Ital 2007;59:105-111.

22 Sahin SH, Cinar SO, Paksoy I, Sut N, Oba S: Comparison between low flow sevoflurane anesthesia and total intravenous anesthesia during intermediate-duration surgery: Effects on renal and hepatic toxicity. Hippokratia 2011;15:69-74.

23 Jin Y, Zhao X, Li H, Wang Z, Wang D: Effects of sevoflurane and propofol on the inflammatory response and pulmonary function of perioperative patients with one-lung ventilation. Exp Ther Med 2013;6:781-785.

24 Modesti C, Sacco T, Morelli G, Bocci MG, Ciocchetti P, Vitale F, Perilli V, Sollazzi L: Balanced anestesia versus total intravenous anestesia for kidney transplantation. Minerva Anestesiol 2006;72:627-635. 


\section{Cellular Physiology Cell Physiol Biochem 2016;38:1631-1642 and Biochemistry \begin{tabular}{l|l} 
DOI: 10.1159/000443103 & (c) 2016 The Author(s). Published by S. Karger AG, Basel \\
www.karger.com/cpb
\end{tabular} \\ Xu et al.: Effects of Propofol and Sevoflurane on Liver Ischemic Reperfusio Injury}

25 Erturk E, Topaloglu S, Dohman D, Kutanis D, Besir A, Demirci Y, Kayir S, Mentese A: The comparison of the effects of sevoflurane inhalation anesthesia and intravenous propofol anesthesia on oxidative stress in one lung ventilation. Biomed Res Int 2014;2014:360936.

26 Lu Y, Jian MY, Ouyang YB, Han RQ: Changes in rat brain microrna expression profiles following sevoflurane and propofol anesthesia. Chin Med J (Engl) 2015;128:1510-1515.

27 Yang SC, Chung PJ, Ho CM, Kuo CY, Hung MF, Huang YT, Chang WY, Chang YW, Chan KH, Hwang TL: Propofol inhibits superoxide production, elastase release, and chemotaxis in formyl peptide-activated human neutrophils by blocking formyl peptide receptor 1. J Immunol 2013;190:6511-6519.

28 Xu Z, Dong M, Fang L, Dong R, Li S: The effect of propofol on the expression of rabbit ischemia reperfusion injury-related proteins. Cell Biochem Biophys 2015;71:1165-1170.

29 Balyasnikova IV, Visintine DJ, Gunnerson HB, Paisansathan C, Baughman VL, Minshall RD, Danilov SM: Propofol attenuates lung endothelial injury induced by ischemia-reperfusion and oxidative stress. Anesth Analg 2005;100:929-936.

30 Yang B, Liang G, Khojasteh S, Wu Z, Yang W, Joseph D, Wei H: Comparison of neurodegeneration and cognitive impairment in neonatal mice exposed to propofol or isoflurane. PLoS One 2014;9:e99171.

31 Cavalcanti V, Santos CL, Samary CS, Araujo MN, Heil LB, Morales MM, Silva PL, Pelosi P, Fernandes FC, Villela N, Rocco PR: Effects of short-term propofol and dexmedetomidine on pulmonary morphofunction and biological markers in experimental mild acute lung injury. Respir Physiol Neurobiol 2014;203:45-50.

32 Zhang Y, Tian SY, Li YW, Zhang L, Yu JB, Li J, Chen YY, Wang YX, Liang Y, Zhang XS, Wang WS, Liu HG: Sevoflurane preconditioning improving cerebral focal ischemia-reperfusion damage in a rat model via pi3k/akt signaling pathway. Gene 2015;569:60-65.

33 Rancan L, Huerta L, Cusati G, Erquicia I, Isea J, Paredes SD, Garcia C, Garutti I, Simon C, Vara E: Sevoflurane prevents liver inflammatory response induced by lung ischemia-reperfusion. Transplantation 2014;98:1151-1157.

34 Wang H, Xue Z, Wang Q, Feng X, Shen Z: Propofol protects hepatic 102 cells from hydrogen peroxideinduced apoptosis via activation of extracellular signal-regulated kinases pathway. Anesth Analg 2008;107:534-540.

35 Elsharkawy AM, Oakley F, Lin F, Packham G, Mann DA, Mann J: The nf-kappab p50:P50:Hdac-1 repressor complex orchestrates transcriptional inhibition of multiple pro-inflammatory genes. J Hepatol 2010;53:519-527.

36 Sun B, Fan H, Honda T, Fujimaki R, Lafond-Walker A, Masui Y, Lowenstein CJ, Becker LC: Activation of $\mathrm{nf}$ kappa $\mathrm{b}$ and expression of icam-1 in ischemic-reperfused canine myocardium. J Mol Cell Cardiol 2001;33:109-119.

37 Sun H, Chen L, Zhou W, Hu L, Li L, Tu Q Chang Y, Liu Q, Sun X, Wu M, Wang H: The protective role of hydrogen-rich saline in experimental liver injury in mice. J Hepatol 2011;54:471-480.

38 Vardanian AJ, Busuttil RW, Kupiec-Weglinski JW: Molecular mediators of liver ischemia and reperfusion injury: A brief review. Mol Med 2008;14:337-345.

39 Zhang W, Wang M, Xie HY, Zhou L, Meng XQ, Shi J, Zheng S: Role of reactive oxygen species in mediating hepatic ischemia-reperfusion injury and its therapeutic applications in liver transplantation. Transplant Proc 2007;39:1332-1337.

40 Zweier JL, Talukder MA: The role of oxidants and free radicals in reperfusion injury. Cardiovasc Res 2006;70:181-190.

41 He L, Lemasters JJ: Regulated and unregulated mitochondrial permeability transition pores: A new paradigm of pore structure and function? FEBS Lett 2002;512:1-7.

42 Shamas-Din A, Kale J, Leber B, Andrews DW: Mechanisms of action of bcl-2 family proteins. Cold Spring Harb Perspect Biol 2013;5:a008714.

43 Du F, Ding Y, Zou J, Li Z, Tian J, She R, Wang D, Wang H, Lv D, Chang L: Morphology and molecular mechanisms of hepatic injury in rats under simulated weightlessness and the protective effects of resistance training. PLoS One 2015;10:e0127047.

44 Syed Hussein SS, Alfarizal Kamarudin MN, Kadir HA: (+)-catechin attenuates nf-kappab activation through regulation of akt, mapk, and ampk signaling pathways in lps-induced bv-2 microglial cells. Am J Chin Med 2015:1-26.

45 Poornima P, Quency RS, Padma VV: Neferine induces reactive oxygen species mediated intrinsic pathway of apoptosis in hepg2 cells. Food Chem 2013;136:659-667. 


\section{Cellular Physiology Cell Physiol Biochem 2016;38:1631-1642 \begin{tabular}{ll|l} 
DOI: 10.1159/000443103 & $\begin{array}{l}\text { O 2016 The Author(s). Published by S. Karger AG, Basel } \\
\text { www.karger.com/cpb }\end{array}$ \\
\cline { 2 - 3 }
\end{tabular} \\ Xu et al.: Effects of Propofol and Sevoflurane on Liver Ischemic Reperfusio Injury}

46 Hsieh CJ, Kuo PL, Hsu YC, Huang YF, Tsai EM, Hsu YL: Arctigenin, a dietary phytoestrogen, induces apoptosis of estrogen receptor-negative breast cancer cells through the ros/p38 mapk pathway and epigenetic regulation. Free Radic Biol Med 2014;67:159-170.

47 Zhou CH, Zhu YZ, Zhao PP, Xu CM, Zhang MX, Huang H, Li J, Liu L, Wu YQ: Propofol inhibits lipopolysaccharide-induced inflammatory responses in spinal astrocytes via the toll-like receptor 4/ myd88-dependent nuclear factor-kappab, extracellular signal-regulated protein kinases1/2, and p38 mitogen-activated protein kinase pathways. Anesth Analg 2015;120:1361-1368.

48 Kim SH, Li M, Pyeon TH, So KY, Kwak SH: The volatile anesthetic sevoflurane attenuates ventilator-induced lung injury through inhibition of erk1/2 and akt signal transduction. Korean J Anesthesiol 2015;68:62-69.

49 Li D, Wang C, Li N, Zhang L: Propofol selectively inhibits nuclear factor-kappab activity by suppressing p38 mitogen-activated protein kinase signaling in human ea.Hy926 endothelial cells during intermittent hypoxia/reoxygenation. Mol Med Rep 2014;9:1460-1466. 